said, it is not only necessary to destroy the laboratory of the poison in the intestine : we must also destroy it in the blood. It is not enough to stand by and wait till the poison is exhausted through the natural channels of excretion. It clings to the blood with a strange obstinacy and seemingly has the power after passing from the blood into the intestine to develop and reconstitute its laboratory. We might by the administration of calomel again cleanse the prime viae, but we do not prevent a fresh infection. No, we must attack it in the blood. In a method of treatment we find the true adaptation of the term specific. It is not enough to use such drugs as iron and carbonate of potash as we do in the anxmia of chlorosis. We have here no vital poison like malaria. Dr. Rustace Smith, in his work on the Diseases of Children, says that in malaria where there is much acute enlargement of the liver and spleen quinine seems to be useless and advocates a treatment with grey powder. I find that quinine has a more favourable action on the poison after the administration of calomel than without it, because probably calomel obviates the biliary derangements which are a feature of quinine. Here we find, I believe, the true and proper application of quinine. I experimented still further on several drugs said to have antiseptic properties on the blood, such as alicylic acid, arsenic, potassium iodide, and carbolic acid. I got the best results from carbolic acid, but better results still by a combination of carbolic acid and quinine. I gave it in the form of a solution in the proportion of $1 \mathrm{gr}$. of carbolic acid to $3 \mathrm{gr}$. of quinine in sulphuric acid and water to $1 \mathrm{oz}$. every four hours till the temperature fell, then less frequently for several days, till the symptoms had disappeared. Almost every case reacted favourably to this treatment. In my hands it has been practically specific. Arsenic is largely used in the French army, partly, I believe, from economical reasons, but the mortality among their troops in Madagascar is a sad proof of its inefficacy. Arsenic diminishes the glycogen of the liver and is thus another plank in favour of the glycogenic theory. In the after treatment the principal object is to nourish the patient, at the same time keeping close watch on the liver, regulating any derangement at once, keeping the paths of excretion open, and giving a diet largely consisting of carbohydrates. Alcohol must be sparingly indulged in; excess is fatal. Another point which is not generally known is that a sea voyage is unfavourable unless the patient is fully convalescent. H.R.H. Prince Henry of Battenberg died at sea; so did Sir William Maxwell. It is a common thing for men to come on board at Beira incompletely convalescent and die before they reach Natal. In many cases men completely convalescent succumb to the terrible black-water fever after being a few hours at sea. What the cause is it is difficult to say. Possibly the motion of the vessel acting through the nerve centres on the vasomotor nerves of the liver may disturb its glycogenic functions, or a chill may be the cause or it may be in the atmosphere itself. Whatever it may be, however, it is a law of malaria which it is well to bear in mind when advising a patient to take the voyage to Europe. It is too frequently the voyage from which none return.

Banchory, Kincardineshire, N.B.

\section{EXTRAORDINARY CASE OF HORSE-BITE;}

\section{THE EXTERNAL EAR COMPLETELY} BITTEN OFF AND SUCCESSFULLY REPLACED

\section{By WILliaM J. BROWN, B.A., M.B. DuB.,} L.R.C.S. IREL.,

CERTIFYING FACTORY SURGEON

ON March 2nd, 1898, at about 4.30 P.M., when present at an auction, I was asked to attend to a boy, aged fourteen years, whose ear had been bitten off by a vicious horse. He presented a hideous appearance, the greater portion of the pinna, together with a semi-circular flap of an inch radins from behind the ear, having been bitten off, leaving only the tragus with a quarter of an inch each of the helix and lobule. (See Fig. 1.) Although the case looked so hopeless (as regards disfigurement) I determined to make an attempt to save the ear, as the patient could be no worse off than be was then if the attempt failed. I

asked for the ear and after about ten minutes' search it was brought to me, having been found near the horse in the stable yard. It was of a dirty drab colour and the posterior flap was curled up in a roll. I had no instruments or dressings with me, and it would have taken half an hour or more to procure them, which delay would have

FIG. 1.

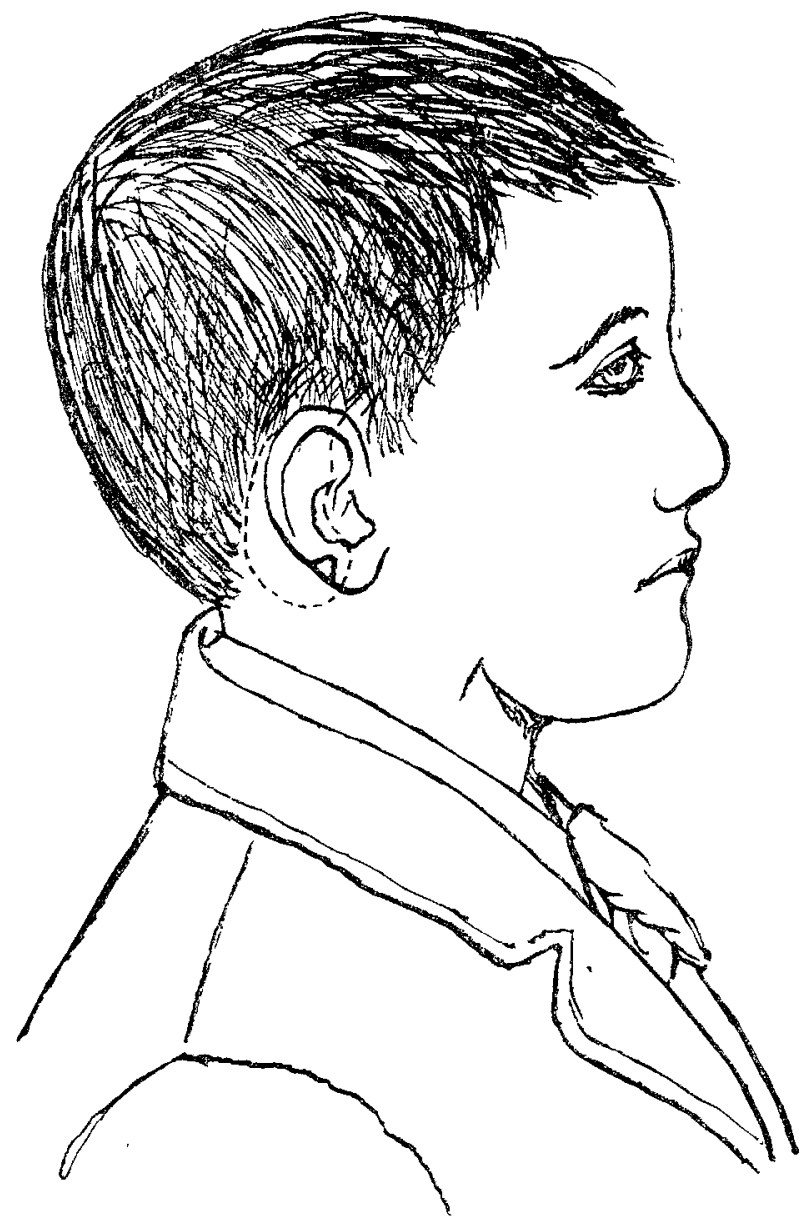

The dotted line indicates the portion of the pinna and tissues behind the ear which were bitten off. A notch in the lobe indicates the spot where sloughing took place.

FIG. 2.

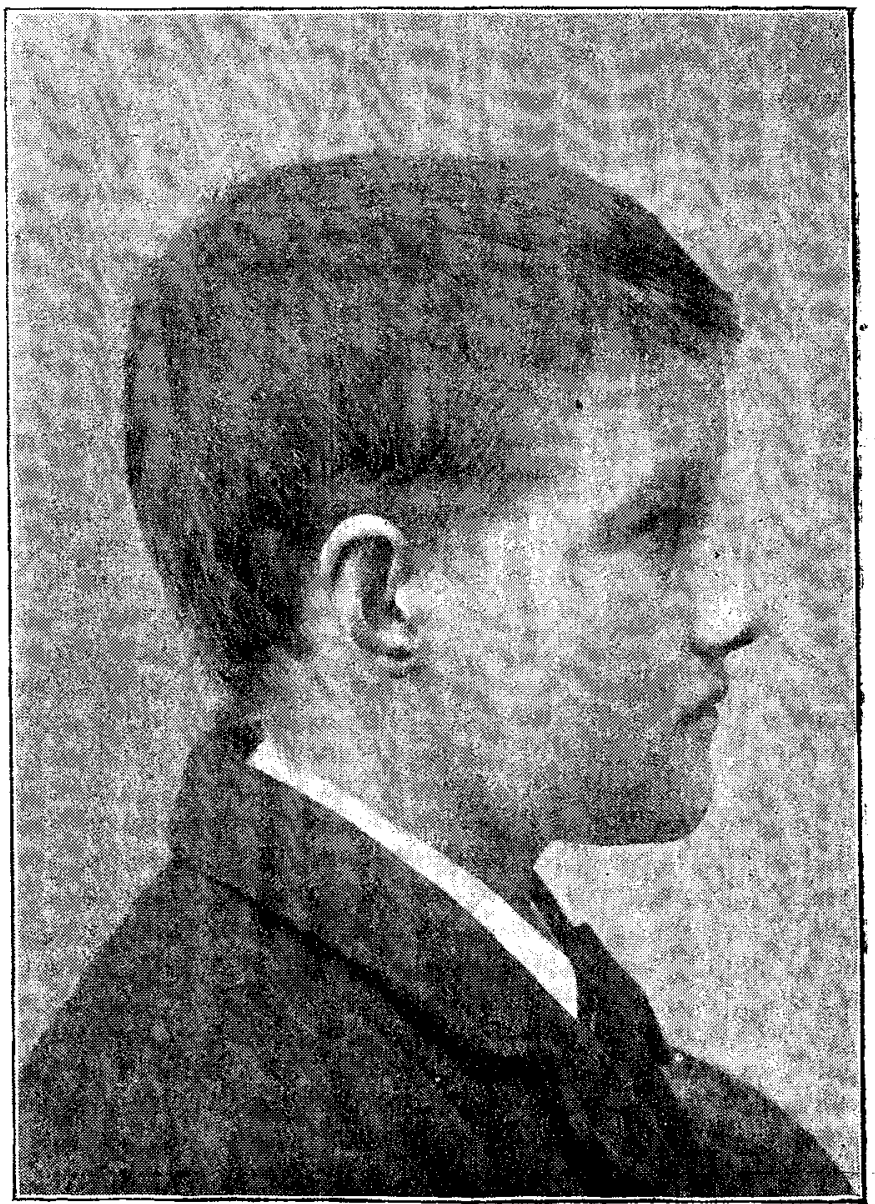

R. J-, aged fourteen years, as he now appears, 
rendered the attempt to preserve the ear useless. I therefore procured some common needles and thread and after washing the ear in warm water I proceeded to sew it on by inserting a suture above and another below, followed by three behind and three before. The posterior flap had to be unrolled before I could stitch it and owing to the needles being straight there was great difficulty in placing the sutures in the concha and the fossa of the antihelix. I then placed a roll of cottion wool behind the ear to support it, and having wrapped it in cotton wool and covered it with a silk handkerchief sent the boy home. As soon after as possible I removed as much of the wool as I could without disturbing the wound, and after dusting the surface with iodoform wrapped the ear in cotton-wool and Gamgee tissue. On March 7th I removed the dressings, washed the ear with a warm solution of bichloride of mercury ( 1 in 1000), dusted the surface with iodoform, wrapped the ear in iodoform gauze, and packed it round and covered it with cotton wool. On the 10th I renewed the dressings and removed the sutures. On the 14th a small portion of the lobe sloughed away. On the 16th the patient looked rather anæmic and felt weak, so he was given a mixture containing sulphate of quinine and tincture of perchloride of iron. The same treatment was adopted throughout, the dressings being renewed every second or third day until April 7th, when they were allowed to remain on until the 12 th, when the ear was completely healed and presented the appearance shown in Fig. 2. The patient's diet consisted of plain food together with bovril, beef-tea, and eggs. He is a healthy, intelligent lad, who has survired several accidents, his body being covered with scars from burns. On one occasion it was necessary to transplant six skin-grafts from the calf of bis leg to his thigh to replace skin which had been destroyed by burns.

This case, I consider, shows what valuable results may be brought about by antiseptic treatment and making prompt ase of whatever comes handy when the proper instruments, \&c., are not available.

Chester-le-Street.

\section{A CASE IN WHICH A STONE WAS DE- TECTED IN THE KIDNEY BY MEANS OF THE X RAYS AFTER SUB- SIDENCE OF ALL SYMPTOMS AND SUCCESSFULLY REMOVED.}

By CHaRles A. MORTON, F.R.C.S. ENG., PROFKESOR OF SURGERY IN UNIVERSITY COLLEGE, BRISTOL, $\triangle N D$ SURGEON TO THE BRISTOL GENERAL HOBPITAI.

THE report of the case of Dr. Taylor and Mr. Fripp at a recent meeting of the Clinical Society of London ${ }^{\mathrm{I}}$ and the interesting discussion on the detection of stones in the kidney by the $x$ rays which followed have induced me to publish the following case.

The patient, a boy, was admitted into the Bristol General Hospital under my care with well-marked symptoms of renal calculus, but these completely subsided with rest in bed and the boy could run about and jump downstairs without any pain and there was no tenderness in the loin on firm pressure or sharp percussion, so that he would certainly have been sent home without operation had the skiagram failed to detect the calculus, as I should have concluded that the stone might have passed down the areter into his bladder or have passed per urethram without recognition. It is interesting to note that this complete subsidence of symptoms had occurred on a previous occasion, when he had been discharged from hospital apparently "cured." Probably when symptoms came on the calculus got out of its pouch in a calyx and moved about in the pelvis of the kidney and the subsidence of these symptoms was due to its falling back into this pouch again. This complete subsidence of symptoms has been observed in other cases when a stone has remained in the kidney, but without the detection of a calculus by $x$ rays a surgeon would hardly like to do nephrotomy after the symptoms had passed off. That the stone in my case was of the oxalate variety made its detection more easy. The skiagram showing it was exhibited (together with the stone) by me at a meeting of the Bristol MedicoChirurgical Socjety last autumn. It was taken by Mr. L. Tyack, lecturer on physics at University College, Bristol.

This patient, aged twelve years, came under my care at the General Hospital on June 28th, 1897, with a history of attacks of severe pain in the left loin. During these attacks he passed urine very frequently. The pain did not shoot into the groin or testes. From the description given by his mother there is very little doubt that he had bæmaturia after an attack. Strong percussion of the left loin seemed to cause some pain, but there was no tenderness on deep and firm pressure on the kidney or in the course of the ureter nor could any stone be felt in the lower end of the ureter per reotum. His bladder had been sounded by the assistant house surgeon before I saw him with negative result. In the previous September he had been a medical in-patient with attacks of lumbar pain. This was the first time he had suffered from the pain and it had not recurred in the interval. He was admitted on June 30 th with a severe attack of pain which lasted twenty-four hours and was accompanied by vomiting but there was no bæmaturia. The pain was felt through the left loin. These attacks recurred for three days and required morphia injections. The muscles over the kidney became rigia and there was much tenderness over the whole of that side of the abdomen and in the loin behind. The urine was carefully watched but no hæmaturia was detected. The note on July 5th says that he had been free from pain for forty-eight hours, but that there was tenderness on pressure in the region of the kidney behind. A skiagram taken on the 8th showed a shadow lying over the twelfth rib, $1 \frac{1}{4}$ in. from the spine. After this skiagram was taken he could run, and jump down several steps, without pain and there was no tenderness on sharp percussion of the loin and firm pressure there. He said the only pain he had was along the urethra after micturition and this had been present since the passage of the bladder sound before admission. However, another skiagram taken on the 14th showed the same shadow as the one taken on the 8th. I operated on Jaly 23rd. Directly I passed my finger round to the anterior surface of the kidney I felt the stone covered by only a thin layer of renal tissue. It lay just where the skiagram seemed to indicate-in front of the last rib and therefore in the upper part of the kidney. After its extraction I could pass $m y$ finger into the dilated calyx in which it had been lying and then on into the pelvis of the kidney, so that I could recognise the apices of the pyramids; I thoroughly sounded the pelvis with a very small bladder sound, but failed to discover any other calculus. The boy made an uneventful recovery and when I saw him a few months ago he was still quite well. The stone was a typical oxalate calculus. It measured $\frac{3}{4}$ in. by $\frac{1}{2}$ in. and on it was a process about $\frac{1}{3}$ in. long, covered with rare and beautiful crystalline oxalates.

Clifton, Bristol.

\section{THE ADMINISTRATION OF CHLOROFORM,} WITH SPECIAL REFERENCE TO AN ADMIXTURE OF ETHER.

BY WILLIAM E. BURTON, L.R.C.S. IREL., LIC. MED. T.C.D.

SURGRON TO THE ROYAL MATERNITY CHARITY AND TAATE RESIDENT SURGEON, RICHMOND HOSPITAL, DURLIN.

IN the controversy which has been carried on concerning the methods and the dangers of chloroformisation it seems a pity that the attention of one set of writers should have been so exclusively directed to the influence of the drug on respiration and of the others, equally exclusively, to its effect on the circulation, the fact being that these functions are so mutually interdependent that serious and continued interference with the one cannot fail to quickly affect the other; and when, as in $\mathrm{CHCl}_{3}$ narcosis, such interference is due to primary and simultaneous inhibitive action on the nerve centres of both it would seem that neither of these functions can be neglected with safety to the patient. In other words, to watch the pulse and the pulse alone is to neglect the breathing which may and usually does give warning of an impending catastrophe the approach of which may not have been appreciable in 